\title{
Comparison of posterior lumbar interbody fusion and transforaminal lumbar interbody fusion in degenerative spondylosis and disc disease in a tertiary care hospital in Pimpri
}

\author{
Harsh Sanjay Kumar, Ajit Swamy*
}

Department of Orthopaedics, Dr. DY Patil Medical College, Pimpri, Pune, India

Received: 21 October 2019

Revised: 27 February 2020

Accepted: 28 February 2020

\section{*Correspondence:}

Dr. Ajit Swamy,

E-mail: ajit.swamy@yahoo.co.in

Copyright: () the author(s), publisher and licensee Medip Academy. This is an open-access article distributed under the terms of the Creative Commons Attribution Non-Commercial License, which permits unrestricted non-commercial use, distribution, and reproduction in any medium, provided the original work is properly cited.

\begin{abstract}
Background: Spinal fusion in the form of transforaminal lumbar interbody fusion (TLIF) and posterior lumbar interbody fusion (PLIF) are the two common surgical modalities for degenerative spondylosis and disc disease. The objective of the study to compare blood loss, surgical timing, post-operative medical and surgical complications in patients treated by either modality.

Methods: This was to compare prospective study of 30 patients equally divided between two modalities operated for TLIF or PLIF after conservative treatment failure.

Results: There is a statistically significant difference between the blood loss, surgical time and improvement in ODI score in two groups while percentage of post-surgical complications are higher in PLIF group compared to TLIF.

Conclusions: TLIF is associated with less post-operative surgical complications than TLIF which can be attributed to unilateral exposure of intervertebral disc space and requires lesser operative time and produces less blood loss.
\end{abstract}

Keywords: TLIF, PLIF, Degenerative spondylosis, Disc disease

\section{INTRODUCTION}

Lumbar spondylosis with degenerative disc disease with facet disease is a common cause of disability of in old age patients. Mechanical back pain, radiculopathy, claudication along with poor of quality of life are common symptoms of lumbar spondylosis and disc disease.

60 to $85 \%$ adult experience low back in their lives with 90 percent of them getting relief with 6 weeks. $15-40 \%$ of the population develops chronic low back ache which does not resolve within 3 months.

Standard choice of treatment for spine pathologies like lumbar spondylosis, degenerative disc disease is spinal fusion. The aim of spinal fusion is to obtain a primary solid arthrodesis and thus decreasing low back ache and improving life quality. ${ }^{1}$ Over the years the method of spinal arthrodesis i.e., spinal fusion has evolved. The approach for spinal fusion can be anterior, posterior, lateral and posterolateral. ${ }^{2}$

Spinal fusion targets solid fixation of spinal segments while maintaining disc height and load bedearing capacity. Interbody fusion also restores lordosis and corrects deformity in addition to providing indirect decompression. ${ }^{1}$

Posterior lumbar interbody fusion (PLIF), transforaminal lumbar interbody fusion (TLIF), oblique lumbar interbody fusion (OLIF), lateral lumbar interbody fusion (LLIF) and 
anterior lumbar interbody fusion (ALIF) are the various techniques of interbody fusion. ${ }^{3}$

ALIF/OLIF/LLIF use a retroperitoneal corridor which is anterior to the transverse process while PLIF/TLIF use a posterior approach which is posterior to the vertebral body. $^{3}$

Cloward in 1940 first described PLIF which involved using a posterior approach enabling three column fixations with 360-degree fusion and anterior support. ${ }^{4}$ Harms described TLIF which consists of using pedicular screws and interbody spacer with a single posterolateral approach. ${ }^{5}$

\section{Technique overview}

Indications for both TLIF and PLIF are the same both these procedures and also have the same contraindications. The advantage of PLIF is it provides a 360 degree fusion using a single incision, posterior approach allows excellent visualization of anatomical structures and it allows for neural decompression while maintaining posterior support structures but with disadvantage of higher incidences of nerve root and dural injury. ${ }^{6}$ The advantage of TLIF is it minimizes injury to nerve roots and dura and provide easy access to structures like ligamentum flavum, facet joint and lamina, provides a bilateral anterior column support. ${ }^{6}$

\section{Aims}

Aim was to evaluate the efficacy and safety of PLIF versus TLIF in degenerative lumbar spondylosis. To evaluate the various complication like blood loss, surgical time, fusion rate, morbidity and hospitilisation time post TLIF and PLIF.

\section{Objectives}

The objective of the study was to compare PLIF and TLIF and to study the safety of TLIF and PLIF.

\section{METHODS}

This was a prospective study conducted in Dr. DY Patil Hospital, Pune in a period from October 2017 to September 2019 and consisted of 30 patients who were divided into two groups using random number table after giving a trial of non-surgical intervention such as physical therapy and analgesics for their spine ailment with having.

\section{Exclusion criteria}

Exclusion criteria were $<18$ years at the time of surgery. Patients with other spinal disorders cause by trauma, scoliosis, tumour or infection and dural tear are excluded from this study. Patients with spinal cord injury has been excluded from this study. Patients having spine disorders caused by metabolic disorders like diabetes and peripheral neuropathies have been excluded in this study.

\section{Inclusion criteria}

Inclusion criteria were $>18$ year at the time of surgery. Disc herniation, spinal stenosis or spondylolisthesis or other types of degenerative disease in adults have been included in the study. Operative time, blood loss, complications and pain or disability improvement in each case have been reported as desirable outcome.

At least 6 months follow up will be taken after surgery. Ethic approval was given for this study by ethics committee of Dr. DY Patil University, Pimpri, Pune.

\section{RESULTS}

In the study consisting of total 30 cases there were 20 cases who had age less than 45 years out of which 10 such cases were in PLIF group and 10 in TLIF group. 5 cases in both groups were above age of 45 years. Out of the total 30 cases 12 cases were male divided equally between two group and rest were female patients also divided equally between the two groups There was no statistical difference between the BMI of two groups with p value being 0.139 the mean BMI was 26.9 in TLIF and in PLIF was 25.Total 10 cases had hypertension (HTN) and diabetes mellitus (DM) which were equally represented in both the groups. Total 2 and 3 cases in PLIF and TLIF group respectively had diabetes only while 1 case had only HTN in TLIF group. On statistical chi square test $\mathrm{p}$ value evaluation there was no significant difference in two groups with $p$ value being 0.184 .

\section{Level operated in two groups}

Single case was operated at L3-L4 level in TLIF group no PLIF case was done for the same while two cases were operated at L4-L5 level by PLIF none by TLIF and five cases were operated by TLIF at L5-S1 level and four cases were done by PLIF and four cases were done by PLIF at L4-L5-S1 level while five where done by TLIF and five cases were done by PLIF at L3-L4-L5 and four cases were done by TLIF.

Table 1: Level operated on in the two groups.

\begin{tabular}{|llllll|}
\hline \multirow{2}{*}{ Comorbidities } & \multicolumn{2}{l}{ PLIF } & \multicolumn{2}{l|}{ TLIF } & Total \\
\cline { 2 - 6 } & $\mathbf{N}$ & $\boldsymbol{\%}$ & $\mathbf{N}$ & $\mathbf{\%}$ & \\
\hline L3-L4 & 0 & 0 & 1 & 6.7 & 1 \\
\hline L4-L5 & 2 & 13.3 & 0 & 0 & 2 \\
\hline L3-L4-L5 & 5 & 33.3 & 4 & 26.7 & 9 \\
\hline L4-L5-S1 & 4 & 26.7 & 5 & 33.3 & 9 \\
\hline L5-S1 & 4 & 26.7 & 5 & 33.3 & 9 \\
\hline Total & 15 & 100 & 15 & 100 & 30 \\
\hline
\end{tabular}

Chi square test $p$ value $=0.504$ (not significant).

Pre- and post-operative back pain with and/or leg pain. This was documented as yes or no depending upon the presence or absence of pain in back with and/or pain post operatively. 4 cases came with residual back and leg pain 
post operatively which were equally represented in two group.

The chi square test value was not significant. Pre operatively all the 30 cases had back pain with radiating pain to lower limb.

Table 2: Pre-operative back pain or leg pain in two groups.

\begin{tabular}{|llllll|}
\hline Back pain & PLIF & \multicolumn{1}{l}{ TLIF } & \\
or leg pain & N & \% & N & $\%$ & Total \\
\hline Yes & 15 & 100 & 15 & 100 & 30 \\
\hline No & 0 & - & 0 & - & 0 \\
\hline Total & 15 & 100 & 15 & 100 & 30 \\
\hline
\end{tabular}

Chi square test $\mathrm{p}$ value $=\mathrm{NA}$.

Table 3: Post-operative back pain or leg pain in two groups.

\begin{tabular}{|llllll|}
\hline \multirow{2}{*}{$\begin{array}{l}\text { Back pain or leg } \\
\text { pain }\end{array}$} & PLIF & \multicolumn{3}{c|}{ TLIF } & Total \\
\cline { 2 - 6 } & $\mathbf{N}$ & $\mathbf{\%}$ & $\mathbf{N}$ & $\mathbf{\%}$ & \\
\hline Yes & 2 & 13.3 & 2 & 13.3 & 4 \\
\hline No & 13 & 86.7 & 13 & 86.7 & 26 \\
\hline Total & 15 & 100 & 15 & 100 & 30 \\
\hline
\end{tabular}

Chi square test $\mathrm{p}$ value $=1.00$ (not significant).

\section{Blood loss}

Comparison between two group also showed a significant difference where $p$ value came out to be 0.002 . The mean blood loss in cases operated for PLIF was $141 \mathrm{ml}$ and TLIF was $125 \mathrm{ml}$ respectively.

Table 4: Blood loss in the two groups.

\begin{tabular}{|c|c|c|c|c|}
\hline Group & Mean & SD & Min-Max & P value \\
\hline PLIF & 141 & 13.3 & $125-160$ & \multirow{2}{*}{$\begin{array}{l}0.002 \\
\text { (significant) }\end{array}$} \\
\hline TLIF & 125 & 12.1 & $115-150$ & \\
\hline
\end{tabular}

\section{Surgical time}

On comparison of between the two groups the surgical time was significantly was significantly lower in TLIF group compared to PLIF group where $\mathrm{p}$ value came out to be 0.003 . The mean operating time was 145 minutes in TLIF and 179 minutes in TLIF.

Table 5: Operating time in the two groups.

\begin{tabular}{|lllll|} 
Group & Mean & SD & Min-Max & P value \\
\cline { 1 - 5 } & 179 & 27.7 & $140-200$ & 0.003 \\
TLIF & 145 & 27.6 & $120-180$ & (significant) \\
\hline
\end{tabular}

\section{Post-operative hospital stays}

The post-operative hospital stay in the two groups was not statically significant with $\mathrm{p}$ value of 0.112 although the mean post-operative stay in PLIF group was 8 days and TLIF group was 5.6 days. The decision to keep patients indoor for a longer time was influenced by post op surgical complications.

Medical morbidities post operatively noted as medical other. There were no medical morbidities like pneumonia, urinary tract infection and DVT post operatively while in cases operated by PLIF a single case developed DVT which as managed by low molecular weight heparin

Table 6: Post-operative hospital stays in the two groups.

\begin{tabular}{|lllll|}
\hline Group & Mean & SD & Min-Max & P value \\
\cline { 1 - 3 } & 8 & 5.2 & $5-18$ & 0.112 (not \\
Significant)
\end{tabular}

Table 7: Medical morbidities postoperatively in the two groups (medical other).

\begin{tabular}{|llllll|}
\hline Medical & \multicolumn{2}{l}{ PLIF } & \multicolumn{2}{l|}{ TLIF } & Total \\
morbidities & N & $\%$ & N & $\%$ & \\
\hline DVT & 1 & 6.7 & 0 & 0 & 1 \\
\hline None & 14 & 93.3 & 15 & 100 & 29 \\
\hline Total & 15 & 100 & 15 & 100 & 30 \\
\hline
\end{tabular}

Chi square test $\mathrm{p}$ value $=0.309$ (not significant).

\section{Post-operative surgical complications}

In the PLIF group there were 3 cases which had a dural tear intraoperatively which were repeated primarily apart from this 1 cases developed great toe dorsiflexion weakness post operatively this resolved spontaneously 3 patients also developed deep infection which had to be taken up for debridement and post which intravenous antibiotics had to be given which lengthened there hospital stay. In TLIF group one case had superficial infection which was treated with sterile dressing and was cured conservatively. There was no irreversible sequalae after any of these complications.

Table 8: Post-operative surgical complications in two groups.

\begin{tabular}{|llllll|}
\hline \multirow{2}{*}{$\begin{array}{l}\text { Complication } \\
\text { PLIF }\end{array}$} & $\mathbf{N}$ & $\mathbf{\%}$ & $\mathbf{N}$ & $\mathbf{\%}$ & Total \\
\hline Deep infection & 3 & 20.0 & 0 & - & 3 \\
\hline $\begin{array}{l}\text { Superficial } \\
\text { infection }\end{array}$ & 0 & - & 1 & 6.7 & 1 \\
\hline Dural tear & 3 & 20.0 & 0 & - & 3 \\
\hline $\begin{array}{l}\text { Great toe } \\
\text { dorsiflexion } \\
\text { weakness post- } \\
\text { operative }\end{array}$ & 1 & 6.7 & 0 & - & 1 \\
\hline None & 8 & 53.3 & 13 & 86.7 & 21 \\
\hline Total & 15 & 100 & 15 & 100 & 30 \\
\hline
\end{tabular}

Chi square test $\mathrm{p}$ value $=0.126$ (not significant). 


\section{Clinical outcome}

This was documented as yes or no depending upon the presence or absence of pain in back with and/or pain post operatively. 4 cases came with residual back and leg pain post operatively which were equally represented in two group. The chi square test value was not significant. Pre operatively all the 30 cases had back pain with radiating pain to lower limb.

Table 9: Pre-operative ODI score in the two groups.

\begin{tabular}{|lllll|}
\hline Group & Mean & SD & Min-Max & P value \\
\cline { 1 - 4 } PLIF & 55.4 & 4.0 & $50-62$ & 0.09 (not \\
\cline { 1 - 4 } TLIF & 57.5 & 2.5 & $54-62$ & significant) \\
\hline
\end{tabular}

Table 10: Post-operative ODI score in the two groups.

\begin{tabular}{|lllll|}
\hline Group & Mean & SD & Min-Max & P value \\
\cline { 1 - 2 } & 22.5 & 3.6 & $15-26$ & 0.002 \\
TLIF & 18.9 & 1.4 & $16-22$ & (significant) \\
\hline
\end{tabular}

\section{DISCUSSION}

Degenerative disease of spine presenting with back pain and radicular symptoms are initially treated physiotherapy, oral medication and rest. Long term incapacitating back pain with radicular symptoms are associated with poor quality of life which also hampers day to day activities of patient. The ultimate gold standard treatment of such degenerative lumbar degenerative pathologies like disc degeneration, spondylosis and spondylolisthesis is interbody fusion.

Preservation of disc height, achievement of solid fusion with decompression of neural tissue and stabilization of the motion segment (in cases of spondylolisthesis) and restoration of sagittal plane translation and rotational alignment are the goals to be achieved for treatment of degenerative disease of lumbar spine operated for interbody fusion.

In our study both the surgical time and blood loss were significantly lesser in the TLIF group owing to the requirement of bilateral exposure in PLIF compared to the requirement of unilateral exposure in TLIF and lesser retraction of thecal sac and neural elements the result of which was in accordance with Mura et al in his paper on TLIF in symptomatic disc degeneration: 100 cases a retrospective study and study by Rezk et al in TLIF VS PLIF in treatment of single level lumbar spondylolisthesis. ${ }^{1,2}$

The study also depicts improvement in the ODI score of patients post operatively in patients operated by TLIF taken at 6 months was statically significant which depicts how clinical outcome of TLIF is superior to PLIF. This reduction in ODI score shows how TLIF reduces the untolerable back pain and increases the quality of life which was in accordance to the study by Adogwa et al oncost effectiveness of TLIF for grade 1 degenerative spondylolisthesis which showed that TLIF reduces pain, disability and quality of life.

The study also shows that surgical complication post operatively like dural tear, deep infection are and neurological deficit are more in the cases operated by PLIF than TLIF in which 7 cases out of 15 had such surgical complications which was in accordance to the studies done by Humphreys et al. ${ }^{8}$ Comparision of posterior and transforminal approaches to lumbar interbody fusion which showed higher complication rate owing to the excessive need of medial retraction of dura to place cage in PLIF technique which increases rate of dura tear and nerve root injury. ${ }^{8}$ Higher cases of dura injury was in accordance to study by Zhang et al which showed that there are higher chances of durotomy in cases of PLIF.

The postoperative hospital mean stay in TLIF compared to PLIF was lower being 5.6 in TLIF and 8 in PLIF group although this data didn't come out to be significant statistically this was in accordance with Hee et al in his study of anterior/posterior lumbar fusion versus transforaminal lumbar interbody fusion : analysis of complications and predictive factors. ${ }^{10}$

In the PLIF group single patient developed post-operative deep vein thrombosis which was treated with low molecular weight heparin.

TLIF and PLIF both the interbody fusion techniques offer circumferential spinal stabilization but TLIF takes a lateral approach to disc space and it preserve the interlaminar space on the opposite side which can be used as a site for additional fusion. Both these techniques can be enhanced when enhanced with posterolateral fusion and instrumentation.

\section{CONCLUSION}

In our study where patients have been matched on the basis of age sex and BMI and there was no significant difference between the two groups and patients who were operated by either modality were given a conservative trial for the cure of back pain have reaffirmed that TLIF is a superior surgical modality compared to PLIF with TLIF having shorter surgical time, less blood loss, lesser percentage of post-operative complications and having a smaller hospital stay when compared with PLIF. The clinical outcome is also better in patients operated with TLIF with Oswestry score index calculated postoperatively had significant statistical difference between two groups.

\section{Funding: No funding sources}

Conflict of interest: None declared

Ethical approval: The study was approved by the institutional ethics committee 


\section{REFERENCES}

1. Mura PP, Costaglioli M, Piredda M, Caboni S, Casoli S. TLIF for symptomatic disc degeneration: a retrospective study of 100 patients. Eur Spine J. 2011;20:57-60.

2. Rezk EMA, Elkhoy AR, Shamhoot EA. TLIF vs PLIF in treatment of single level lumbar spondylolisthesis. Egyptian J Neuro Surg. 2019;34:26-34.

3. Mobbs RJ, Phan K, Malham G, Seex K, Rao PJ. Lumbar interbody fusion: techniques, indications and comparisons of interbody fusion options including PLIF, TLIF, MI-TLIF, OLIF, LLIF and ALIF. J Spine Surg. 2015;1:2-18.

4. Cloward RB. The treatment of ruptured intervertebral disc by verterbral body fusion Indications, operative technique, after care. J Neurosurg. 1953;10:154-68.

5. Harms JG, Jeszenszky D. The unilateral transforaminal approach for posterior lumbar interbody fusion. Orthop Traumatol. 1998;6:88-99.

6. Zhang B, Yuan CG, Zheng BL, Hao DJ. Transforaminal lumbar interbody fusion versus posterolateral fusion in Degenerative lumbar spondyolosis. Medicine (Baltimore). 2016;95(40):4995
7. Adogwa O, Parker SL, David BJ, Aaronson O, Devin C, Cheng JS, et al. Cost effectiveness of transforaminal lumbar interbody fusion for grade 1 degenerative spondylolisthesis. J Neurosurg Spine. 2011;15(2):211.

8. Humphreys SC, Hodges SD, Patwardhan AG. Comparison of posterior and transforaminal approaches to lumbar interbody fusion. Spine. 2001;26:567-71.

9. Zhang Q, Yuan Z, Zhou M, Liu H, Xu Y, Ren Y, et al. Comparison of TLIF and PLIF: a literature review and meta-analysis. BMC Musco Skeletal Disorders. 2014; 15:367.

10. Hee HT, Castro FP, Majd ME, Holt RT, Myers L. Anterior/posterior lumbar fusion versus transforaminal lumbar interbody fusion: analysis of complications and predictive factors. J Spinal Disord. 2001;14:533-40.

Cite this article as: Kumar HS, Swamy A.

Comparison of posterior lumbar interbody fusion and transforaminal lumbar interbody fusion in degenerative spondylosis and disc disease in a tertiary care hospital in Pimpri. Int J Res Orthop 2020;6:730-4. 